\title{
Produção de mudas de pitaya com diferentes segmentos de cladódio e reguladores de crescimento vegetal
}

\author{
Nursery production of pitaya with different segments of cladodium and plant growth regulators \\ Producción de plántulas de pitaya con diferentes segmentos de cladodio y reguladores del \\ crecimiento de las plantas
}

\section{Resumo}

O presente trabalho teve como objetivo avaliar a aplicação de regulares vegetais e biofertilizante no desenvolvimento de segmentos de cladódios e formação de mudas da espécie Selenicereus setaceus. O experimento foi instalado em esquema fatorial $5 \times 4 \times 7$, sendo 5 tratamentos: biofertilizante, auxina 500 ppm, giberelina 100 ppm, citocinina 200 ppm e testemunha; quatro segmentos de cladódios: apical, mediano, basal $(10 \mathrm{~cm})$ e inteiro $(40 \mathrm{~cm})$ e sete períodos de avaliação: 0, 20, 39, 64, 91, 116 e 143 dias após o plantio. Os cladódios tratados com auxina apresentaram maiores médias de comprimento e massa seca de raiz, enquanto que, aqueles tratados com biofertilizante menores. A massa seca de raiz de cladódios inteiros foi superior a observada em segmentos menores. Os tratamentos com cladódio inteiro e região basal apresentaram maiores médias de número de brotações em comparação as regiões mediana e apical. Os tratamentos com auxina e citocinina promoveram maior número de brotações nos cladódios. O maior comprimento de brotações foi observado para o tratamento com cladódios inteiros.

Palavras-chave: Fruta dragão; Selenicereus setaceus; Fitormônios; Propagação vegetativa; Cactaceae.

\begin{abstract}
The objective of this work was to evaluate the application of plant regulators and biofertilizers in the development of cladodes segments and formation of seedlings of the species Selenicereus setaceus. The experiment was set up in a $5 \times 4 \times 7$ factorial scheme, 5 treatments: biofertilizers, auxin 500 ppm, gibberellin 100 ppm, cytokinin 200 ppm and control. Four cladodes fractions: apical segment, median segment, basal segment $(10 \mathrm{~cm})$ and whole cladodes $(40 \mathrm{~cm})$ and seven evaluation periods, 0, 20,39, 64, 91, 116 and 143 days after planting. The cladodes treated with auxin presented higher mean lengths of root and dry matter, while those treated with biofertilizer showed lower ones. The root dry mass of whole cladodes $(40 \mathrm{~cm})$ was higher than that observed for segregated regions of cladodes. The treatments with whole cladode and basal region presented higher average number of shoots compared to the median and apical regions. The auxin and cytokinin treatments promoted a greater number of sprouts in the cladodes. The longer sprouting length is observed for treatment with whole cladodes.
\end{abstract}

Keywords: Dragon fruit; Selenicereus setaceus; Phytohormones; Vegetative propagation; Cactaceae. 


\section{Resumen}

El presente trabajo tuvo como objetivo evaluar la aplicación de reguladores del crecimiento de las plantas y biofertilizantes en el desarrollo de segmentos de cladodios y formación de plántulas de la especie Selenicereus setaceus. El experimento se instaló en un esquema factorial $5 \times 4 \times 7$, con 5 tratamientos: biofertilizante, auxina 500 ppm, giberelina 100 ppm, citoquinina 200 ppm y control; cuatro segmentos de cladodios: apical, mediano, basal (10 $\mathrm{cm})$ y entero $(40 \mathrm{~cm})$ y siete períodos de evaluación: $0,20,39,64,91,116$ y 143 días después de la siembra. Los cladodios tratados con auxina mostraron mayor longitud media y materia seca de la raíz, mientras que los tratados con biofertilizantes más pequeños. La masa seca de la raíz de los cladodios enteros fue mayor que la observada en segmentos más pequeños. Los tratamientos con cladodio completo y región basal mostraron promedios de número de brotes más altos en comparación con las regiones mediana y apical. Los tratamientos con auxina y citoquinina promovieron un mayor número de brotes en los cladodios. La mayor longitud de brote se observó para el tratamiento con cladodios enteros.

Palabras clave: Fruta del dragón; Selenicereus setaceus; Fitohormonas; Propagación vegetativa; Cactaceae.

\section{Introdução}

O Brasil é o terceiro maior produtor de frutas do mundo, sendo superado apenas pela China e Índia (MAPA, 2018). Essa atividade possui elevado efeito multiplicador de renda, permitindo a dinamização de economias locais, estagnadas e com poucas alternativas de desenvolvimento. Assim, o plantio de espécies frutíferas tem se tornado uma excelente opção de diversificação para agricultura familiar em pequenas propriedades rurais, assumindo um importante papel socioeconômico, por absorver intensa mão de obra familiar e resultar em alto rendimento econômico por área (Tomazi, et al., 2016).

Dentre as espécies de frutíferas com potencial econômico destaca-se a pitaya, por sua adaptação e rusticidade, apresentando alta produtividade mesmo em condições adversas de ambiente, como déficit hídrico e extremos de temperaturas (Lone, 2010). No Brasil a pitaya tem sido considerada uma frutífera exótica, no entanto, são encontradas espécies de pitaya nativas no Cerrado e matas de transição, principalmente espécies do gênero Selenicereus e Hylocereus, dentre elas a Selenicereus setaceus Rizz., popularmente conhecida como pitaya-do-cerrado ou "saborosa" (Junqueira, et al., 2002).

$\mathrm{O}$ fruto da pitaya possui polpa firme e sabor doce e suave, características que proporcionam grande aprovação dos mercados consumidores. Seu consumo é normalmente realizado in natura como refrescos, geleias, doces, iogurtes e sorvetes, sendo utilizado também em medicina caseira, contra gastrites e redutor de níveis de colesterol (Donadio, 2009). O cladódio (ramos de caule modificado com presença de clorofila) tem sido utilizado como cicatrizante e a semente como laxante natural (Junqueira, et al., 2002). Além disso, os frutos apresentam alto valor nutricional e atividade antioxidante na polpa e na casca (Mello, 2014; Santos, et al., 2016).

O cultivo da pitaya torna-se uma alternativa de renda para a agricultura familiar, podendo ser implantada em espaços pedregosos, não mecanizáveis, capaz de tolerar extremos de temperatura, solos com baixo nível de fertilidade e grandes períodos de estiagem (Nunes, et al., 2014).

Embora o custo de implantação não seja baixo, principalmente pelo preço elevado das mudas, as pitayas produzem em média de 15 a 20 anos e sua produção pode alcançar $20 \mathrm{t} \mathrm{ha}^{-1}$ (Hessen \& Tellez, 1995), com preços variando entre $\mathrm{R} \$ 11,00 \mathrm{a}$ $\mathrm{R} \$ 60,00$ o Kg do fruto. Além disso, a pitaya é uma alternativa na implantação de sistemas agroflorestais, sendo uma espécie epífita de produção precoce, possibilita renda ao agricultor logo no segundo ano após sua implantação (Zee, et al., 2004; Le Bellec, et al., 2006).

A pitaya pode ser propagada por meio de sementes ou de forma vegetativa, por estaquia, esta última é mais atrativa, por possibilitar a uniformização do plantel e por produzir frutos precocemente (Hernández, 2000). Entretanto, as sementes constituem importante forma de propagação, por permitir a variabilidade genética, tornando possível a seleção de características desejáveis em programas de melhoramento (Andrade, et al., 2008; Ruths, et al., 2019). 
Por se tratar de uma frutífera tropical pouco conhecida, existem poucas informações de pesquisa, de ordem prática para os agricultores, sobre a cultura. Dentre esses conhecimentos, a otimização da metodologia de propagação vegetativa, a partir de pequena quantidade de material propagativo é de fundamental importância para êxito econômico da cultura.

A produção de mudas constitui-se em uma das etapas mais importantes do sistema produtivo, influenciando no desempenho da planta, pois mudas de qualidade apresentam maior percentual de crescimento e sobrevivência, dispensando replantio, diminuindo custos com manutenção e oferecendo capacidade de resistência a situações adversas no pós-plantio (Cruz, et al., 2006). Devido a isso, o emprego de estratégias que favoreçam o crescimento rápido da muda torna-se premente, principalmente no período inicial da vida da planta. O sucesso da instalação de matrizes é garantido pelo uso de mudas de alta qualidade, homogêneas, de rápida formação e com precocidade de produção de frutos.

Assim, o objetivo do trabalho foi avaliar o efeito da aplicação de biofertilizante e três reguladores vegetais no enraizamento de diferentes segmentos de cladódios e produção de mudas da espécie Selenicereus setaceus.

\section{Metodologia}

O experimento foi conduzido na casa de vegetação da Universidade Federal da Fronteira Sul, Campus Laranjeiras do Sul, Laranjeiras do Sul, PR, cujas coordenadas geográficas da região são $25^{\circ} 26^{\prime} 42^{\prime \prime}$ de latitude Sul e 52 $26^{\prime} 29^{\prime \prime}$ longitude Oeste, $850 \mathrm{~m}$ de altitude.

Os cladódios de pitaya (S. setaceus) foram adquiridos com agricultores no município de Jacinto Machado no Vale de Araranguá, SC. Os cladódios foram selecionados pela sanidade e pelo tamanho de aproximadamente $40 \mathrm{~cm}$. Após, obteve-se quatro segmentos de cladódios: inteiro com $40 \mathrm{~cm}$ (não identificado na Figura 1), segmento apical, basal e mediano, todos com $10 \mathrm{~cm}$, conforme Figura 1A, B e C, respectivamente.

Os segmentos foram obtidos cortando-se o cladódio inteiro a $10 \mathrm{~cm}$ do ápice e da base e para o segmento mediano descartou-se $5 \mathrm{~cm}$ de cada lado do cladódio restante.

Figura 1. Desenhos esquemáticos dos segmentos de cladódios de pitaya: A - segmento apical; B - segmento basal; C segmento mediano.

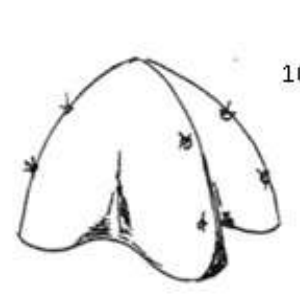

A

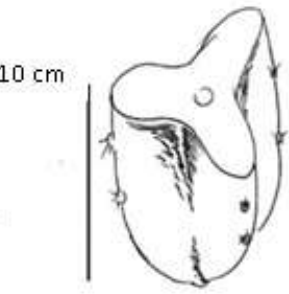

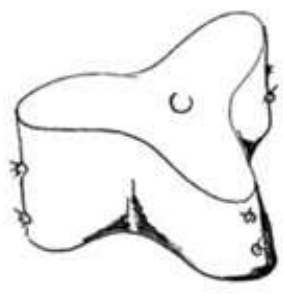

C

Fonte: Marques, et al., (2012) com modificações

De posse de todos os segmentos de cladódio, estes foram colocados em sacos de polietileno $(15 \times 25 \mathrm{~cm})$ contendo 40 $\%$ de substrato comercial, $30 \%$ de terra peneirada e $30 \%$ de areia peneirada. Os tratamentos utilizados foram: biofertilizante comercial Fish Fértil - Classic ${ }^{\circledR}$ diluído na proporção de $2 \mathrm{~mL}$ para $500 \mathrm{~mL}$ de água destilada, auxina (AIA) na concentração de 500 ppm, ácido giberélico $\left(\mathrm{GA}_{3}\right)$ na concentração de 100 ppm e 6 - benzilaminopurina (BAP), na concentração de 200 ppm.

Os cladódios tratados com auxina foram colocados com a extremidade basal imersa na solução por 24 horas antes do plantio, na ausência de luz. Já nos tratamentos com biofertilizante, giberelina e citocinina foram realizadas aspersões aos 0, 20, 39, 64, 91, 116 e 143 dias após o plantio dos cladódios. 
Os segmentos de cladódios permaneceram durante todo o experimento em casa de vegetação com temperatura em torno de $25{ }^{\circ} \mathrm{C}$ e umidade relativa de $60 \%$. A irrigação foi realizada duas vezes ao dia por 4 minutos $(1,2 \mathrm{~L} /$ bico por minuto $)$ às 09:00 h da manhã e às 15:00 h da tarde. A cada período de tempo em que se realizou a aspersão dos tratamentos avaliou-se o número de brotações, comprimento de brotações $(\mathrm{cm})$ e largura dos cladódios a $5 \mathrm{~cm}$ do solo $(\mathrm{cm})$. Ao final do experimento foram realizadas avaliações do comprimento do sistema radicular $(\mathrm{cm})$, massa seca de raiz $(\mathrm{g})$ e percentual de cladódios enraizados e confeccionadas lâminas permanentes para observação de amiloplastos.

Para a confecção das lâminas permanentes, o cladódio de $S$. setaceus foi cortado transversalmente com espessura de 0,5 cm e colocado em F.A.A na proporção 10:85:5 \% (Formaldeído 37 \%, Etanol $95 \%$ e Ácido Acético Glacial) por 48 horas. Após a retirada do material do F.A.A foi realizada a desidratação, constituída por cinco etapas de duas horas em álcool 50, 70, 85, 95 e 100\%, e duas etapas de 12 e 24 horas com Álcool Butílico Terciário (TBA). Após a desidratação foi realizada a diafanização a vácuo, que consistiu numa série etanol-xilólica, sendo: TBA - Xilol (3:1, 1:1, 1:3, 0:1) com duração de 1 hora cada etapa. Para a impregnação, o material vegetal foi colocado em parafina líquida na estufa a $60{ }^{\circ} \mathrm{C}$ por 12 horas, seguido de uma troca de parafina e impregnação por mais 8 horas. Após a impregnação foi realizada a inclusão, onde os tecidos foram colocados no interior de um molde contendo parafina líquida e deixado secar. Os cortes foram realizados no micrótomo com espessura de $7 \mu \mathrm{M}$, colocados em água gelatinada e "pescados" com a lâmina.

Para proceder a coloração utilizou-se o procedimento inverso, para a retirada da parafina, hidratando o material: Xilol puro (3x), Xilol-álcool etílico (3:1, 1:1, 1:3), Álcool etílico $100 \%$ (2x), Álcool etílico (95, 85, 70 e 50 \%), cada etapa em período de 10 minutos. Após realizou-se dois banhos em água destilada por 2 minutos, colocou-se uma gota de Lugol por 10 minutos e lavou-se novamente com água destilada. Foi colocado sobre a lâmina a resina Permount, e posteriormente, a lamínula e deixado secar. A observação foi realizada em microscópio de luz da marca Olympus.

$\mathrm{O}$ delineamento experimental utilizado foi o inteiramente casualizado com três repetições e as parcelas foram compostas por cinco cladódios. O experimento foi instalado em esquema fatorial $5 \times 4 \times 7$, sendo cinco tratamentos: um biofertilizante, três reguladores vegetais (auxina, giberelina, citocinina) e testemunha, quatro segmentos de cladódios: segmento apical $(10 \mathrm{~cm})$, segmento mediano $(10 \mathrm{~cm})$, segmento basal $(10 \mathrm{~cm})$ e cladódio inteiro $(40 \mathrm{~cm})$ e sete períodos de avaliações: 0, 20, 39, 64, 91, 116, 143. Os dados foram submetidos à análise de variância pelo software SISVAR, e as médias comparadas pelo teste de Tukey a 5 \% de significância (Ferreira, 2011).

\section{Resultados e Discussão}

Ao final do experimento, 143 dias após o plantio dos cladódios, foi constatado 100\% de enraizamento, independente do tratamento utilizado. Esse resultado indica que Selenicereus setaceus é de fácil enraizamento. Bastos et al., (2006); Lone \& Takahashi (2019); Marques et al., (2012); Pontes Filho et al., (2014), trabalhando com a espécie de pitaya Hylocereus undatus Britton. \& Rose, também relataram facilidade de enraizamento dos cladódios.

No entanto, nem todas as espécies de pitaya são de fácil enraizamento, Balaguera-López et al., (2010), estudando o processo propagativo da espécie Selenicereus megalanthus (K. Schum. ex Vaupel) Moran, relataram que estacas com $40 \mathrm{~cm}$ e sem aplicação de auxina apresentaram $40 \%$ de enraizamento e $70 \%$ para estacas com $60 \mathrm{~cm}$ e aplicação de auxina. Silva (2014), também encontrou baixo percentual de enraizamento de estacas de $S$. megalanthus com $10 \mathrm{~cm}(62,5 \%)$ e com $30 \mathrm{~cm}$ $(50 \%)$.

Para a variável comprimento da raiz não houve diferença significativa entre os tratamentos com auxina, giberelina, citocinina e testemunha (Tabela 1). No entanto, cladódios tratados com bioferitlizantes foram os que apresentaram menores médias de comprimento de raiz, não diferindo estatisticamente dos tratamentos testemunha, citocinina e giberelina. É 
importante salientar que, o comprimento da raiz está diretamente relacionado com a absorção de água e nutrientes minerais presentes nos substratos, podendo influenciar positiva ou negativamente no processo de formação de mudas.

Silva, (2014), avaliando produtos oriundos de resíduo da indústria pesqueira na produção de mudas de pitaya Hylocereus polyrhizus (Weber) Britton e Rose também encontrou resultados negativos em relação a testemunha para crescimento de raízes. No entanto, Boracin et al., (2016) testando o efeito do biofertilizante Vetor 1000® na concentração de 1 $\mathrm{ml} \mathrm{L}^{-1}$ no enraizamento de Saintpaulia ionantha Wendl., verificaram que este biofertilizante, a base de peixe, induziu o desenvolvimento radicular e a formação de brotações desta espécie. Mudas com sistema radicular pronunciado poderão tolerar melhor as adversidades bióticas e abióticas das condições de campo aos quais as plantas estão expostas, contribuindo para o adequado estabelecimento da planta.

Tabela 1 - Médias de comprimento e da massa seca das raízes de S. setaceus em função dos cladódios submetidos a cinco diferentes tratamentos após 143 dias do plantio.

\begin{tabular}{ccc}
\hline Tratamentos & Comprimento de raiz $(\mathrm{cm})$ & Massa seca $(\mathrm{g})$ \\
\hline Auxina & $41,17 \mathrm{a}$ & $2,08 \mathrm{a}$ \\
Giberelina & $37,33 \mathrm{ab}$ & $1,02 \mathrm{~b}$ \\
Citocinina & $37,00 \mathrm{ab}$ & $1,27 \mathrm{~b}$ \\
Testemunha & $35,67 \mathrm{ab}$ & $1,22 \mathrm{~b}$ \\
Biofertilizante & $34,92 \mathrm{~b}$ & $1,32 \mathrm{~b}$ \\
\hline
\end{tabular}

Médias seguidas da mesma letra na coluna não diferem estatisticamente entre si pelo teste de Tukey a 5\% de probabilidade. Fonte: Autores

Na Tabela 1, observa-se que o tratamento que propiciou maior acúmulo de matéria seca de raiz foi o com auxinas diferindo de todos os demais tratamentos, os quais não diferiram entre si. A aplicação de auxina exógena promove maior porcentagem, velocidade, qualidade e uniformidade de enraizamento (Cajazeira \& Corrêa, 2014; Hartmann, et al., 2011). Por outro lado, cladódios tratados com giberelina apresentaram médias de massa seca de raiz menor que as observadas nos demais tratamentos, entretanto, diferiu estatisticamente apenas daquela do tratamento com auxina.

Há relatos na literatura sobre a interferência da giberelina no enraizamento de estacas, em concentrações relativamente altas esse hormônio inibe a formação da raiz (Kochba, et al., 1974; Ribeiro, et al., 2006). Como as concentrações de fitormônios variam de acordo com a região do caule, possivelmente, quantidades endógenas da giberelina no cladódio podem ter influenciado na ação da mesma. No entanto, Santos et al., (2010), encontrou que, para maracujazeiros amarelos (Passiflora edulis Sims), pulverizações realizadas com $\mathrm{GA}_{3}\left(78\right.$ e $\left.92 \mathrm{mg} \mathrm{L}^{-1}\right)$, proporcionam aumentos significativos na massa seca de raízes.

$\mathrm{Na}$ Tabela 2 observa-se que, o tamanho e a região do cladódio influenciaram na massa seca das raízes formadas. Quando se utilizou cladódios inteiros $(40 \mathrm{~cm})$ a massa seca de raiz foi superior ao observado para os cladódios segmentados. Todavia, embora as regiões basal, mediana e apical do cladódio utilizado como estaca tivessem o mesmo comprimento (10 $\mathrm{cm}$ ), a região mediana proporcionou ganhos de matéria seca de raiz maior do que a região apical, não diferindo da região basal. Segundo Hartmann, et al., (2011), o enraizamento geralmente difere com o tipo e região da estaca utilizada para a propagação vegetativa. 
Tabela 2 - Médias da massa seca da raiz de S. setaceus em função das regiões (segmentos) de cladódios.

\begin{tabular}{cc}
\hline Tratamentos & Médias $(\mathrm{g})$ \\
\hline Inteira & $2,66 \mathrm{a}$ \\
Meio & $1,17 \mathrm{~b}$ \\
Base & $1,03 \mathrm{bc}$ \\
Ápice & $0,72 \mathrm{c}$ \\
\hline
\end{tabular}

Médias seguidas da mesma letra, na coluna não diferem estatisticamente entre si pelo teste de Tukey a 5\% de probabilidade. Fonte: Autores.

O cladódio inteiro, de maior tamanho, pode ter se constituído numa vantagem em relação aos demais, visto que, reservas mais abundantes de carboidratos correlacionam-se com maiores porcentagens de enraizamento, pelo fato da formação celular requerer energia e esqueletos de carbono para biossíntese de novas biomoléculas (Fachinello, et al., 2005). Neste contexto, cladódios maiores apresentam capacidade de armazenamento de maiores quantidades de amido que servirão de substrato para a divisão celular. Os cladódios de S. setaceus armazenam, no parênquima fundamental do caule, grandes quantidades de amido em organelas denominadas de amiloplastos (Figura 2).

Figura 2 - Amiloplastos em cladódios de S. setaceus. Setas indicam amiloplastos (coloração violeta à preta) contendo amido no parênquima fundamental de cladódios de S. setaceus.

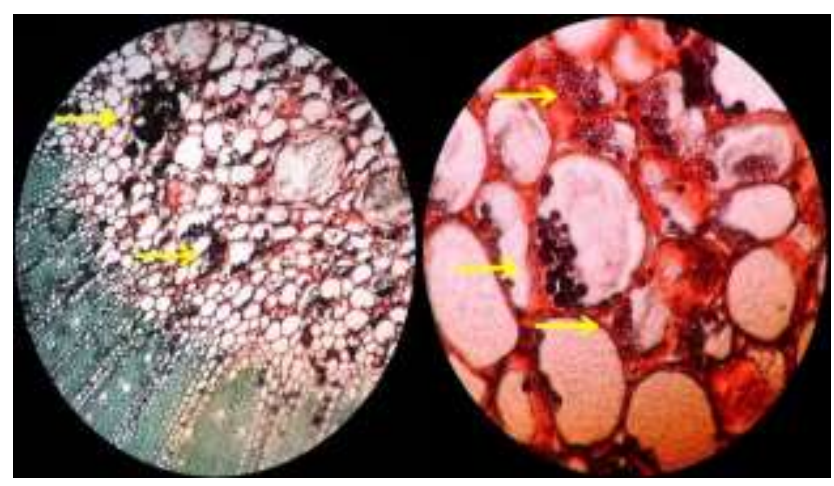

Fonte: Autores.

Durante os primeiros 20 dias de implantação do experimento não foi observada diferença significativa para o número de brotações formadas em relação às diferentes segmentações de cladódios avaliadas (Figura 3). Isso pode ser atribuído ao pequeno número de raízes neste período, restringindo água e nutrientes minerais para a parte aérea, prejudicando às divisões e expansões celulares essenciais para a formação de brotações. Além disso, deve-se considerar que nesta situação o sistema radicular torna-se o dreno mais forte da planta fazendo com que os fotoassimilados sejam direcionados preferencialmente para esta região. 
Figura 3 - Média do número de brotações em função da região (segmento) do cladódio e do período de dias após o plantio. Letras maiúsculas: comparam as médias de "número de brotações" de cada região de cladódio entre os períodos de avaliações (dias); letras minúsculas: comparam as médias de "número de brotações" de cada região de cladódio para cada período de avaliação (dia).

Inteiro 日Base maio $\mathbf{0}$ Ápice

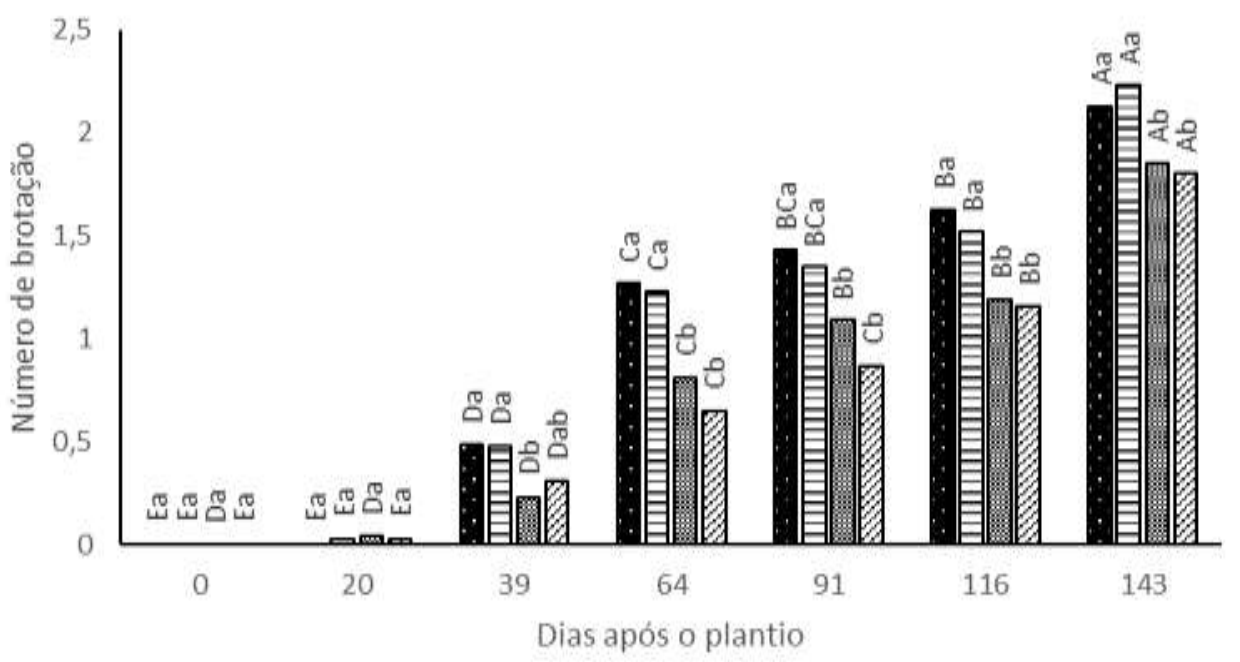

Fonte: Autores.

A partir de 39 dias após a implantação do experimento, o tratamento com cladódio inteiro e o segmento da base apresentam maiores médias de número de brotações em comparação aos segmentos do meio e apical. Este comportamento se estendeu até o final do experimento. O segmento de cladódio inteiro apresenta maior quantidade de reservas nutritivas, hidratos de carbono, hormônios e seus cofatores, consequentemente, obterá maior aporte para produzir quantidades superiores de brotações, do que as regiões segmentadas.

Lima (2013), avaliando a taxa de enraizamento e de número de brotações de Hylocereus undatus em três diferentes tamanhos de cladódios, verificou que as estacas maiores (com nove gemas) proporcionaram maiores quantidades de brotações e desenvolvimento de mudas, e correlacionou o resultado com a grande quantidade de reservas nutritivas presentes nas estacas maiores. Ressalta-se que o número de brotações é de fundamental importância para o produtor de mudas, pois cada brotação consiste em potencial muda que carrega consigo todas as características da planta mãe.

Aos 143 dias após o plantio dos cladódios, embora não diferindo da região inteira, a segmentação da base emitiu maior número de brotações. Possivelmente, a quebra da dominância apical liberou a emissão de brotações dessa segmentação em comparação com os cladódios inteiros e ápice (com dominância apical).

As segmentações mediana e apical do cladódio foram as que formaram menor número de brotações, exceto aos 39 dias após o plantio. O baixo número de brotações emitidos pelo segmento apical pode estar correlacionado com os níveis hormonais do segmento do cladódio, especialmente da auxina, que é produzida principalmente nas regiões meristemáticas apicais de folhas jovens e caules do vegetal e tem como efeito fisiológico na planta a dominância apical, a qual inibe a formação de novas brotações (Ayala-Tafoya, et al., 2020).

Outra hipótese admitida é a menor espessura do caule da região apical em comparação as demais regiões, diminuindo a capacidade de acúmulo de carboidratos de reserva e, com isso, a disponibilidade de esqueletos de carbono e de energia para a formação das novas brotações. Já a região mediana pode ter produzido menores quantidades de brotações em relação ao 
cladódio inteiro e segmento basal em virtude de ter sofrido dois cortes, na extremidade apical e basal. Com isso, parte das reservas nutritivas do cladódio pode ter sido destinada para a cicatrização de suas extremidades.

Na Figura 4 está apresentado o número de brotações formadas em função dos tratamentos e dos dias após o plantio. Verifica-se que, até os 91 dias após o plantio não houve diferença estatística para número de brotações entre os tratamentos. Provavelmente, isto tenha ocorrido em função da partição de fotoassimilados para o estabelecimento do sistema radicular (dreno prioritário) em detrimento da parte aérea do cladódio. De acordo com Taiz et al., (2016) os tecidos drenos competem pelos fotoassimilados translocados e o fator determinante do padrão de transporte é a força do dreno.

Nas duas últimas avaliações (116 e 143 dias após o plantio) os cladódios tratados com auxina e citocinina apresentaram as maiores emissões de brotações, não diferindo estatisticamente entre si, embora o tratamento com citocinina não tenha diferenciado dos tratamentos com biofertilizante e giberelina.

A formação das brotações está relacionada com a capacidade dos tecidos vegetais sofrerem rápidas divisões celulares, liberando as gemas da dominância apical (Botin \& Carvalho, 2015). O principal fitormônio envolvido nessas atividades é a citocinina, amplamente conhecida pelo seu envolvimento no ciclo celular e na supressão da dominância apical (Pillary \& Railton, 1983). Por outro lado, o maior número de brotações para o tratamento com auxina pode ser atribuído ao sistema radicular mais desenvolvido desse tratamento, aumentando o aproveitamento de nutrientes minerais e água.

Os cladódios tratados com biofertilizante e giberelina não diferiram daqueles sem tratamento (Figura 4). Segundo Porto et al., (2018), as giberelinas quando utilizadas na forma exógena estão mais associadas à promoção de crescimento da parte aérea e sua aplicação pode promover aumentos na altura das plantas.

Figura 4 - Média do número de brotações formadas em função dos tratamentos e do período em dias após a plantio. Letras maiúsculas: comparam as médias de "número de brotações" de cada tratamento entre os períodos de avaliações (dias); letras minúsculas: comparam as médias de "número de brotações" de cada tratamento para cada período de avaliação (dia).

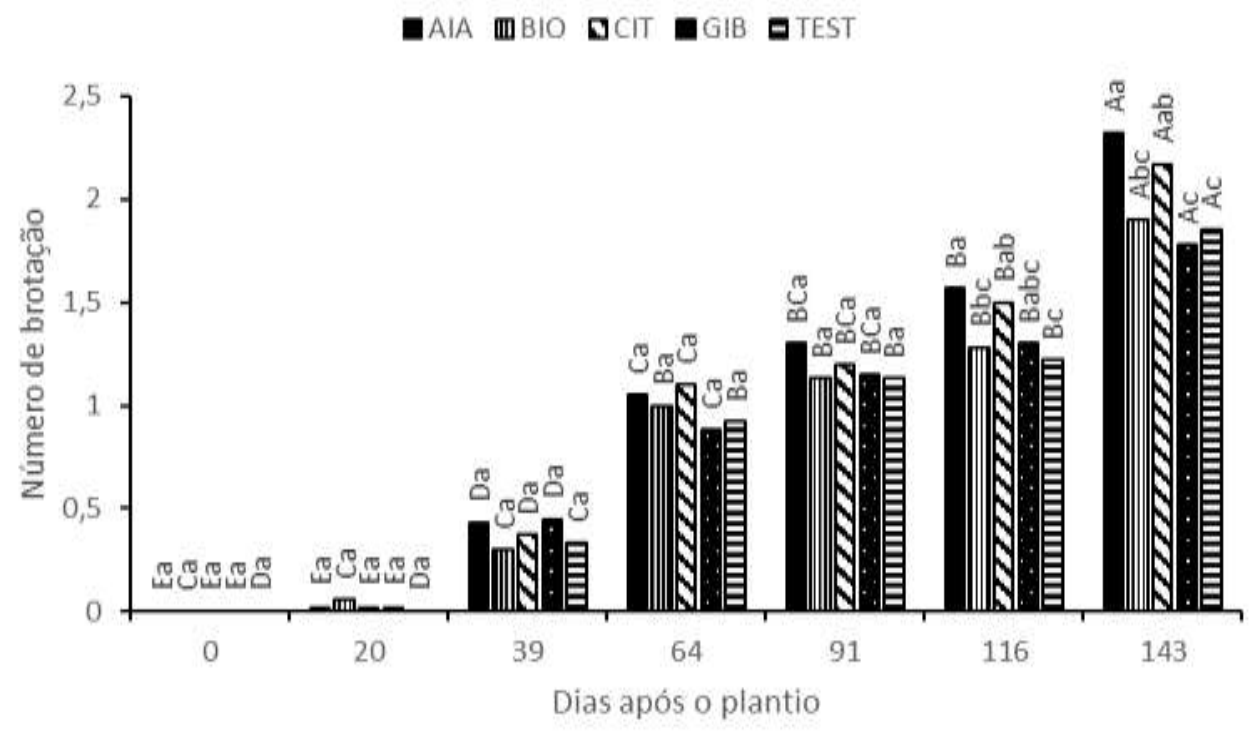

Fonte: Autores.

A análise de variância demonstrou interação entre os tratamentos e as regiões de cladódios (Figura 5) para o número de brotações. No geral, observa-se que cladódios inteiros e da região basal, independentemente do tratamento, foram os que apresentaram maior número de brotações. Por outro lado, a região apical foi onde se observou o menor número. 
Para os tratamentos com cladódios inteiros e do segmento basal, os reguladores de crescimento auxina e citocinina favoreceram o aumento de número de brotações. Todavia nos segmentos apical e mediano não foi verificada diferença estatística entre os tratamentos (Figura 5). A explicação para um maior número de brotações nos tratamentos com auxina e citocinina, pode, no primeiro caso, ser atribuída ao sistema radicular melhor desenvolvido neste tratamento, favorecendo a absorção de água e nutrientes minerais. No segundo, deve-se a capacidade das citocininas de modificar a dominância apical e promoverem o crescimento de gemas laterais (Taiz, et al., 2016).

Figura 5 - Média do número de brotações formadas em função do tratamento e da região (segmento) de cladódios. Letras maiúsculas: comparam as médias de "número de brotações" entre cada região para todos os tratamentos; letras minúsculas: comparam as médias de "Número de brotações" entre as regiões por tratamento.

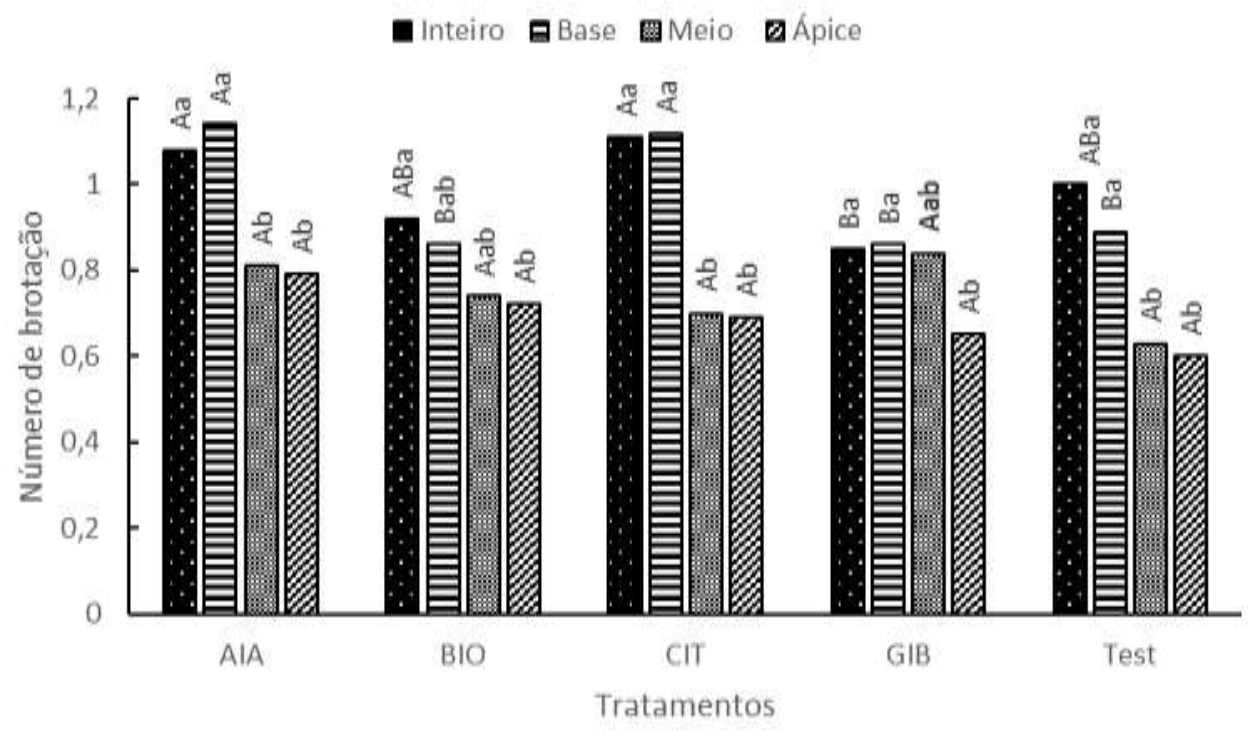

Fonte: Autores.

Para a variável comprimento de brotações, houve a interação entre os segmentos de cladódios e tratamentos. Maiores comprimentos de brotações foram obtidos em cladódios inteiro seguido por cladódios do segmento basal e mediano, os quais não diferiram entre si, e por último o apical (Figura 6). Estes resultados corroboram com Lima (2013) e Pontes Filho et al., (2014), que demonstraram que estacas maiores, por apresentarem maiores quantidades de reservas, resultam em brotações com maiores comprimentos.

No geral, observa-se pela Figura 6 que os tratamentos não influenciaram no comprimento das brotações formadas, independentemente do tamanho e do segmento de cladódio utilizado para o plantio, exceção feita para cladódio do segmento apical tratado com biofertilizante, citocinina e giberelina e cladódio do segmento mediano tratado com citocinina que apresentaram menores médias de comprimento de brotações em relação aos demais tratamentos. 
Figura 6 - Média de comprimento das brotações em função da interação entre as regiões de cladódio (segmento) e dos tratamentos. Letras maiúsculas: comparam as médias de "comprimento de brotações" entre cada região para todos os tratamentos; letras minúsculas: comparam as médias de "comprimento de brotações" entre cada região por tratamento.

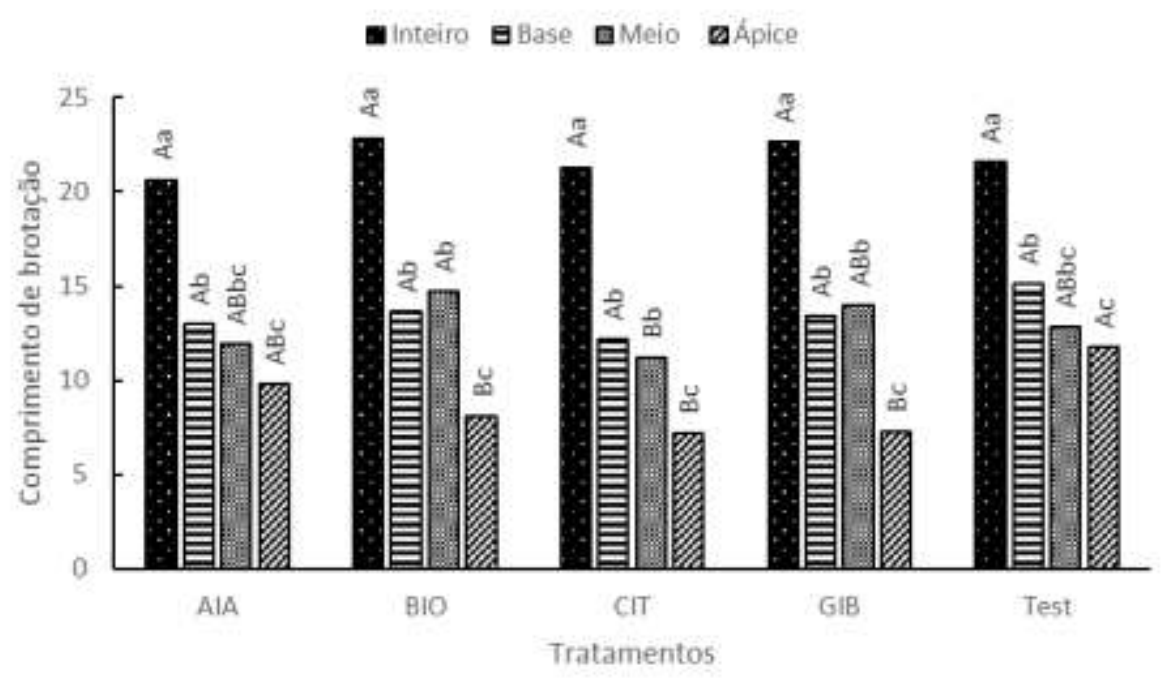

Fonte: Autores.

Até o $39^{\circ}$ dia as médias dos comprimentos das brotações não diferiram estatisticamente entre si independentemente do tamanho e do segmento de cladódio utilizado para o plantio (Figura 7). Aos 64 dias após o plantio foi observado menor comprimento de brotações para o segmento de cladódio apical quando comparado as demais regiões utilizadas para o plantio e nas três últimas avaliações, 91, 116 e 143 dias após o plantio, o cladódio inteiro se destacou com o maior comprimento de brotações, diferenciando-se estatisticamente das demais.

A disponibilidade de carboidratos é fator limitante de sobrevivência dos cladódios, pois constituem a principal fonte de energia assimilável para a manutenção de suas atividades metabólicas (Veierskov, 1988). Estacas maiores apresentam abundancia de reservas, possibilitando maior metabolismo de carboidratos e, consequentemente, contribuindo para um crescimento vigoroso, pois apresentam alta disponibilidade de energia e carbono estrutural para a formação de novos tecidos.

Os segmentos basal e mediano não diferiram estatisticamente entre si quanto ao comprimento das brotações, sendo estes maiores do que o observado no segmento apical. 
Figura 7 - Média de comprimentos das brotações em função da interação entre as regiões de cladódio (segmento) e do período em dias após a plantio. Letras maiúsculas: comparam as médias de "comprimento das brotações" de cada região de cladódio entre os períodos de avaliações (dias); letras minúsculas: comparam as médias de "comprimento de brotações" de cada região de cladódio para cada período de avaliação (dia).

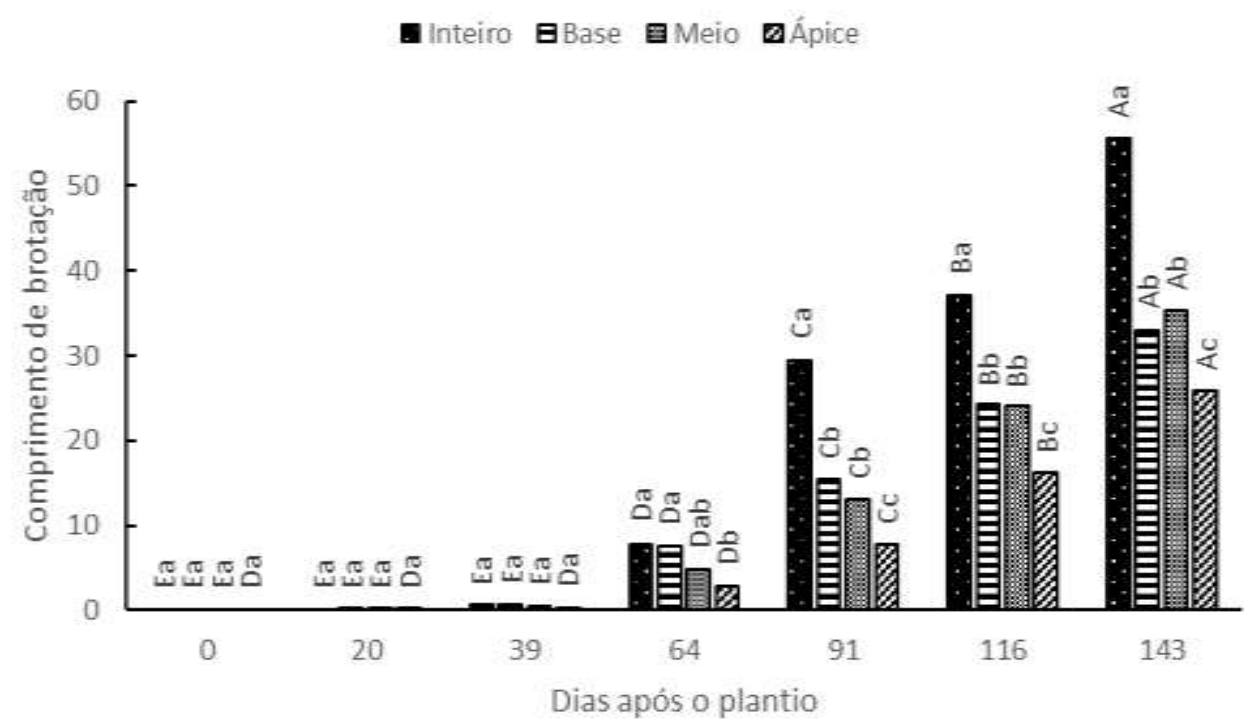

Fonte: Autores.

Na Tabela 3 observa-se que o segmento de cladódio apical apresentou menor média de largura em comparação aos demais segmentos e ao cladódio inteiro. Este resultado era esperado, visto que, os cladódios apresentam um afinamento conforme se aproxima da extremidade apical. É provável que esta seja a explicação para cladódios deste segmento apresentarem menores número de brotações e comprimento de brotações. Por possuírem menor massa, apresentam reduzida estrutura celular para armazenamento de reservas orgânicas.

Tabela 3 - Média da largura dos cladódios de S. setaceus em função de diferentes segmentos de cladódios.

\begin{tabular}{cc}
\hline Tratamentos & Médias $(\mathrm{cm})$ \\
\hline Inteira & $4,22 \mathrm{a}$ \\
Meio & $4,04 \mathrm{a}$ \\
Base & $4,81 \mathrm{a}$ \\
Ápice & $3,16 \mathrm{~b}$ \\
\hline
\end{tabular}

Médias seguidas da mesma letra na coluna não diferem estatisticamente entre si pelo teste de Tukey a 5\% de probabilidade.

Fonte: Autores.

\section{Conclusão}

Os cladódios tratados com auxina apresentaram maiores médias de comprimento de raiz e matéria seca, enquanto que, aqueles tratados com biofertilizante menores.

A massa seca de raiz de cladódios inteiros $(40 \mathrm{~cm}$ ) foi superior a observada em segmentos menores (basal, mediano e apical de $10 \mathrm{~cm}$ ). 
A partir de 39 dias após a implantação do experimento, os tratamentos com cladódio inteiro e região basal apresentaram maiores médias de número de brotações em comparação as regiões mediana e apical.

Os tratamentos com auxina e citocinina promoveram maior número de brotações nos cladódios.

O maior comprimento de brotações foi observado no tratamento com cladódios inteiros.

\section{Agradecimentos}

Os autores agradecem à Universidade Federal da Fronteira Sul pela aprovação do projeto de pesquisa PES 2020-0405 na chamada $N^{\circ}$ 270/2020 - Fomento à iniciação científica, tecnológica e de inovação e fomento à pesquisa com ênfase na pósgraduação stricto sensu da UFFS.

\section{Referências}

Andrade, R. A., Oliveira, I. V. M., Silva, M. T. H. \& Martins, A. B. G. (2008). Germinação de pitaya em diferentes substratos. Revista Caatinga, 21(1),71-75. https://periodicos.ufersa.edu.br/index.php/caatinga/article/view/610/258

Ayala-tafoya, F., López-urquídez, G. A., Parra-delgado, J. M., Retes-manjarrez, J. E., López-orana, C. A. \& Yáñez-juárez, M. G. (2020). Vermicomposta, auxinas sintéticas y producción de calabacita (Cucurbita pepo L.) en invernadero. Terra Latinoamericana, 38(2),257-265. https://www.researchgate.net/p ublication/341031238_Vermicompost_synthetic_auxins_and_greenhouse_production_of_gray_squash_Cucurbita_pepo_L

Bastos, D. C., Pio, R., Scarpare Filho, J. A., Libardi, M. N., Almeida, L. F. P., Galuchi, T. P. D. \& Bakker, S. T. (2006). Propagação da pitaya 'vermelha'por estaquia. Ciência e Agrotecnologia, 30(6), 1106-1109. https://www.scielo.br/scielo.php?script=sci_arttext\&pid=S1413-70542006000600009

Balaguera-López, H. E., Morales, E. I., Almanza-Merchán, P. J. \& Balaguera-López, W. A. (2010). El tamaño del cladodio y los niveles de auxina influyen en la propagación asexual de pitaya (Selenicereus megalanthus Haw.). Revista Colombiana de Ciencias Hortícola,s 4(1), 33-42. https://revistas.uptc.edu.co/index.php/ciencias_horticolas/article/view/1222

Boracin, M. A., Kozusny-Andreani, D. I. \& Andreani Junior, R. (2016). Efeito de bactérias rizosféricas e fertilizantes no enraizamento de violeta africana. Revista da Universidade Vale do Rio Verde, 14(1), 366-375. http://periodicos.unincor.br/index.php/revistaunincor/article/view/2487/pdf_447

Botin, A. A. \& Carvalho, A. (2015). Reguladores de crescimento na produção de mudas florestais. Revista de Ciências Agroambientais, $13(1)$, 83-96.

Cajazeira, J. P. \& Corrêa, M. C. M. (2014). Comprimento de estacas e concentrações de ácido indolbutírico (AIB) na propagação vegetativa de pitaya. Revista Ciência Agronômica, 45, 788-793. https://www.researchgate.net/publication/275276855_Comprimento_de_estacas_e_concentracoes_de_aci do_indolbutirico_AIB_na_propagacao_vegetativa_de_pitaia

Cruz, C. A. F., Paiva, H. N. \& Guerrero, C. R. A. (2006). Efeito da adubação nitrogenada na produção de mudas de sete-cascas (Samanea inopinata (Harms) Ducke). Revista Árvore, 30(4), 537-546. https://www.scielo.br/pdf/rarv/v30n4/31674.pdf

Donadio, L. C. (2009). Pitaya. Revista Brasileira de Fruticultura, 31(3), 637-929. https://www.scielo.br/pdf/rbf/v31n3/a01v31n3

Fachinello, J. C., Hoffmann, A., Nachtgal, J. C. \& Kersten, E. (2005). Propagação vegetativa por estaquia. In: Fachinello, J. C., Hoffmann, A. \& Nachtgal, J. C. Propagação de Plantas Frutíferas. Brasília: Embrapa Informação Tecnológica.

Ferreira, D. F. (2011). Sisvar: A computer statistical analysis system. Ciência e Agrotecnologia, 35, 1039-1042. https://www.scielo.br/pdf/cagro/v35n6/a01v35n6.pdf

Hartmann, H. T., Kester, D. E., Davies, R. T. \& Geneve, R. L. (2011). Plant propagation: principles and practices. Prentice Hall.

Hernández, Y. D. O. (2000). Hacia el conocimiento y la conservación de la pitahaya (Hylocereus spp). Oaxaca: IPN.

Hessen, A. J. \& Tellez, A. (1995). La pitaya se abre paso! Cultivo exótico com pontecial para exportación para las regiones tropicales de la America Latina. Agricultura de lás Américas.

Junqueira, K.P., Junqueira, N. T. V., Ramos, J. D. \& Pereira, A. V. (2002). Informações preliminares sobre uma pitaya (Selenicereus setaceus Rizz.) nativa do cerrado. Belém: Anais do $17^{\circ}$ Congresso Brasileiro de Fruticultura.

Kochba, J., Button, J., Spiegel,-Roy, P., Bornman, C. H. \& Kochba, M. (1974). Stimulation of rooting of citrus embryoids by gibberellic acids and adenine sulphate. Annals of Botany, 38(4), 795-802.

Le Bellec, F., Vaillant, F. \& IMBERT, E. (2006). Pitahaya (Hylocereus spp.): a new fruit crop, a market with a future. Fruits 61(4), 237-250. https://doi.org/10.1051/fruits:2006021

Lima, C. A. (2013). Caracterização, propagação e melhoramento genético de pitaya comercial e nativa do cerrado. Tese140 f., Universidade Federal de Brasília, Brasília. https://repositorio.unb.br/bitstream/10482/12930/1/2013_Cristiane\%20Andrea\%20de\%20Lima.pdf

Lone, A. B. (2010). Temperaturas e substratos na germinação de sementes de genótipos de pitaya. Dissertação 60 f., Universidade Estadual de Londrina, Londrina. http://www.bibliotecadigital.uel.br/document/?code=vtls000154673 
Lone, A. B. \& Takahashi, L. S. A. (2019). Enraizamento e brotação de estacas de pitaya em diferentes períodos do ano. Revista Técnico-Científica do CREA$P R$ 22, 1-13. http://creaprw16.crea-pr.org.br/revista/Sistema/index.php/revista/article/view/597/430

MAPA. Ministério da Agricultura, Pecuária e Abastecimento. Notícias: MAPA vai lançar plano para aumentar exportações de frutas, (2018). http://www.agricultura.gov.br/noticias/mapa-vai-lancar-plano-para-aumentar-exportacoes-de-frutas.

Marques, V. B., Moreira, R. A., Ramos, J. D., Araújo, N. A. \& Cruz, M. C. M. Porções de cladódios e substratos na produção de mudas de pitaya vermelha. Revista Agrarian 5(17), 193-197. https://pitaya-pitaia.webnode.com.pt/files/20000017271e2f72b21/1090\%20Porçoes\%20de\%20cladódios\%20e\%20substratos\%20na\%20produção\%20de\%20mudas\%20de\%20pitaia\%20vermelha.pdf

Mello, F. R. (2014). Avaliação das características físico-químicas e atividade antioxidante da pitaya e determinação do potencial do mesocarpo como corante natural para alimentos. Tese 100 f., Universidade Federal do Paraná, Curitiba. https://hdl.handle.net/1884/36526

Nunes, E. M., Lucena, C. M., Sousa, A. S. B., Silva, S. M., Lucena, R. F. P., Alves, C. A. B. \& Alves, R. E. (2014). Pitaya (Hylocereus sp.): uma revisão para o Brasil. Gaia Scientia, 8, 90-98. https://www.researchgate.net/publication/267326934_Pitaia_Hylocereus_sp_Uma_revisao_para_o_Brasil

Pillary, I. \& Railton, I. D. (1983). Complete release of axillary buds from apical dominance in intact, lightgrown seedlings of Pisum sativum L. following a single application of cytokinin. Plant Physiology, 71(4), 972-974. 10.1104/pp.71.4.972

Pontes Filho, F. S. T., Almeida, E. I. B., Barroso, M. M. A., Cajazeira, J. P. \& Corrêa, M. C. M. (2014). Comprimento de estacas e concentrações de ácido indolbutírico (AIB) na propagação vegetativa de pitaya. Revista Ciência Agronômica, 45(4), 788-793. https://www.researchgate.net/publicati on/275276855_Comprimento_de_estacas_e_concentracoes_de_acido_indolbutirico_AIB_na_propagacao_vegetativa_de_pitaia

Porto, A. H., Wagner Júnior, A., Kosera Neto, C., Silva, M., Stefeni, A. R. \& Fabiane, K. C. (2018). Giberelina e substrato na produção e qualidade de mudas de araçazeiro amarelo e vermelho. Colloquium Agrariae, 14(1), 35-48. https://www.researchgate.net/publication/3251 35270_GIBERELIN A_E_SUBSTRATOS_NA_PRODUCAO_E_QUALIDADE_DE_MUDAS_DE_ARACAZEIROS_AMARELO_E_VERMELHO

Ribeiro, M. N. O., Pasqual, M., Villa, F. \& Albuquerque, K. S. (2006). Efeitos do AIB e GA3 na micropropagação de Zantedeschia aethiopica. Ceres, 53(309), 568-57. http://www.ceres.ufv.br/ojs/index.php/ceres/article/view/3183/1075

Ruths, R., Bonome, L. T. S., Tomazi, Y., Siqueira, D. J., Moura, G. S. \& Lima, C. S. M. 2019. Influência da temperatura e luminosidade na germinação de sementes das espécies: Selenicereus setaceus, Hylocereus undatus e Hylocereus polyrhizus. Revista Ciência e Agroveterinárias, 18(2), 194-201. http://www.revistas.udesc.br/index.php/agroveterinaria/article/view/10891/pdf

Santos, C. A. C., Vieira, E. L., Peixoto, C. P., Benjamim, D. A. \& Santos, C. R. S. (2010). Crescimento inicial de plantas de maracujazeiro amarelo submetidas à giberelina. Comunicata Scientiae, 1(1), 29-34. https://agris.fao.org/agris-search/search.do?recordID=DJ2012062133

Santos, M. R. P. V., Castro, J. C., Mardigan, L. P., Watanabe, R. \& Clemente, E. (2016). Características físico-químicas, compostos bioativos, atividade antioxidante e enzimática de frutos de pitaya (Hylocereus undatus). Revista Brasileira de Tecnologia Agroindustrial 10(1), 2081-2095. Doi:10(1):2081-2095.

Silva, A. C. C. (2014). Pitaya: melhoramento e produção de mudas. Tese 132 f., Universidade Estadual Paulista Júlio de Mesquita Filho, São Paulo.

Taiz, L., Zeiger, E., Moller, I. M. \& Murphy, A. (2016). Fisiologia e desenvolvimento vegetal. (6a ed.), Artmed.

Tomazi, Y., Ruths, R., Siqueira, D. J. \& Bonome, L. T. S. (2016). Influência de reguladores de crescimento, biofertilizantes e segmentos de cladódios na propagação vegetativa de pitaya. Anais do VI Jornada de Iniciação Científica e Tecnológica. https://rd.uffs.edu.br/handle/prefix/610

Veierskov, B. (1988). Relations between carbohydrates and adventitious root formation. Advances in plant sciences series.

Zee F., Yen, C-R., \& Nishina, M. (2004). Pitaya (Dragon Fruit, Strawberry Pear). Fruits and Nuts, 9, 1-3. https://www.researchgate.net/publication/29737580_Pitaya_Dragon_Fruit_Strawberry_Pear 